however, any readily apparent argument against the theory that it has been all dry land and at one and the same time. Let us for a while assume that it was, and let us then see what facts about climate we may infer with regard to it.

There are no doubt many other places besides those already known where the depth exceeds 3,000 fathoms. Let us, however, take the group of the known three which run in a line north-east and south-west, and are respectively $3,450,3,200,3,250$, and we may assume that they represent a valley line. Let us suppose that the area is raised till this valley is dry land; what then will be the height of our ridge, and what will be the highest peaks of the country? To the north-west of the valley, distant about as far as from here to the Grampians, would tower the peaks, now the islands of St. Paul's Rocks, and Fernando de Noronha, rising some 30,000 feet; and to the south-east would rise Ascension to a similar height. The "ridge" itself would be about 15,000 feet. There is no reason whatever for supposing that the ridge is a table land. On the contrary, it seems more probable, judging from the variations in the soundings, that it was diversified with hills and valleys. Now a ridge of this elevation would, in all probability, have a snow capping even at the equator. Astronomers tell us that in "former" times the earth's atmosphere was higher and its pressure greater than now, but that was in a very remote past, and we may fairly assume that at the time of this ridge being land the atmospheric conditions were much as now. We should thus have a mountain ridge with hot valleys and every variation in temperature according to height; so that so far as temperature is concerned botanists would have no difficulty in accounting for the migration across the equator of plants that would be killed by great heat. With regard to the part of the ridge between Europe and America, ans wering to Unger's "Atlantis," the soundings are more numerous. The undulations seem to have been many, and the general elevation was probably not more than 9,000 feet, unless the original depths are masked considerably by a deposit of globigerina-ooze. Some peaks - now the Azores-still remain above water. When the ridge sank is a question on which we have at present no evidence. The whole subject is still young, and we have much yet to learn.

In conclusion the lecturer said : I hope I have given sufficient prominence to the distinction that must be drawn between fact and inferences from those facts.

I should be very sorry for anyone to go away from this place and say that they heard a lecture at South Kensington in which they were told that there formerly was a continent running down the middle of the Atlantic, and that there was a lofty mountain ridge along it, capped with snow even at the equator.

I wish carefully to point out to you I have made no statement of the kind. I have simply told you the fact that a ridge less than I, runs down mid Atlantic in a sinuous course, whose contour is roughly indicated by the diagram. That on each side of it are ocean depths, twice and in some cases thrice the distance it is below the sea-level. That if these depths were once land valleys, as geologists have no difficulty in believing possible, then there would be a ridge running north and south along the area of what is now the deep Atlantic, ranging from 9,000 to I 5,000 feet above the sea-level, and that if the atmospheric conditions were the same then as now, judging from what we know of the Andes under the equator at the present time, there was probably a snow-capping.

Such a land-connection between Europe and America, if it existed as late as Tertiary times, would meet the requirements of Unger's hypothesis, varying in height as it sank, and the whole ridge would afford a solution of any difficulty botanists may have on the score of temperature in accounting for the migration of cold-loving and heatshunning plants across the torrid zone.

The remarks at the conclusion of the lecture, in reference to its being the last of the series, we have already reported at p. 490 .

\section{REMARKS ON THE INVESTIGATION OF} CLIMATES

TO Prof. Balfour Stewart we are indebted for the separation of meteorology into its two great divisions of physical and climatic. The latter I have proposed to separate into two sub-divisions, viz, nomal and abnormal. The first of these subordinate branches includes the investigation of the usual states of the atmosphere in different parts of the earth's surface, as ascertained by periodic data derived from the averages of observations continued for a series of years. The second subordinate branch has for its object the investigation of unusual temporary disturbances of the equilibrium of the atmosphere-such, for example, as storms of wind, by means of the comparison of individual observations, extending over only a few hours or a few days.

We need hardly wonder at the disfavour with which meteorology is regarded by some men of the highest standing in physical science, from whom valuable assist* ance might have been expected; for we know that there is a great want of agreement among meteorologists themselves as to the means of determining even the most im. portant fundamental data. For example, it will hardly, one would think, be disputed that the essential condition in all meteorological inquiries is uniformity in instrumental obseration. But towards the establishment of a uniform international system no progress has as yet been made. Points of subordinate importance may have been adjusted at the Congress meetings at Leipzic and Vienna, but this all-important question remains just where it was. To Mr. Glaisher is due the adoption among his observers of the uniform height of 4 feet above the ground for thermometers, and one invariable form of screen for protecting them. The Scottish Meteorological Society, when estabiishing their stations in 1855 , followed the example of Mr. Glaisher by adopting the 4-feet standard height, and they ultimately selected the form of double-louvre boarded protecting box, which I proposed in 1864 . The Meteorological Society of England have also adopted the same uniform system as that in Scotland of boxes, and their exposure, and hours of observation. But other observers follow different methods, and on the Continent it is believed there is still less approximation to uniformity than among ourselves. The very first matter which should be taken up by home and foreign meteorologists is the settlement once for all of the questions how, when, and with what position and exposure of instruments are observations to be made. Until this is done it is impossible to arrive at useful results, because the observations which are now being obtained at different stations are not comparable the one with the other. Unless there be some such general Council as that lately proposed in NATURE by Prof. Balfour Stewart for carrying out this and other important objects, I shall certainiy despair of the future of this new science.

But let us now see in what way the mode of instrumental observation bears on the subject of climate. Climates may be defined as states of the atmosphere due to the joint operation of geographical, geological, and other conditions more or less local, and they are judged of by their effects on animal and vegetable life. They do not, therefore, depend simply on the geographical position on the earth's surface of the district where the observations are made, but are largely affected by varicus conditions, such as the distribution of lard and water, the nature of the soil and its covering, and the elevation or depression and character of the land at, and 
adjacent to, the place. Climates are, therefore, frequently of a local nature, by which I mean of small superficial extent. Thus many varieties of climate may coexist about the same parallel of latitude, and even over a very limited portion of that zone. Instead of saying, then, that a whole country such as Britain has a certain mean temperature, as ascertained by lumping togethex observations made at places of widely different character, level, and exposure, we should rather say that there are in that island mountainous districts with a certain mean temperature, districts of open plain, having another, and sheltered districts and valleys having another; while parts near the sea-shore, have their own peculiar characteristics. To take a familiar case, we may refer to the Isle of Wight, all parts of which, small though the island be, can hardly have the same climate as Bonchurch and Ventnor, which are the favourite retreats of invalids in pursuit of health. That such local atmospheric distinctions do really exist may at once be shown by a reference to the varied distribution of plant life which, though no doubt largely affected by the nature of the soil, is nevertheless to a considerable extent dependent on the existence of certain atmospheric conditions.

If meteorological stations were to be established in some place situate in a low latitude-such, for example, as the Island of Java, we should be told, as I have more than once been in similar cases, that though 4 feet above the ground may be suitable for thermometers in Britain, it would be quite preposterousfor so hot a climate as Java. Now if what were wanted was to ascertain the amount of heat emitted directly by the sun, such a statement might be correct; for then the instruments should be kept as clear of terrestrial influence as possible, and by taking proper precautions we might perhaps make our observations indifferently at sea or onland. But these would not be observations of climate. Now, as in the case we have supposed, it is the climates of Java and Britain that are to be compared by ascertaining the amount of heat communicated to thermometers by conduction and convection of the air which has been heated by solar, and cooled by terrestrial radiation, the observations must be made on the islands themselves and not on the sea which surrounds them, and by instruments placed at the same level above the surface of the ground. It has been farther objected that in very hot countries there are large districts where canes or other kinds of jungle vegetation rise much above the level of the thermometers, while in Britain there is generally a grassy sward nearly 4 feet below them. These differing kinds of vegetation nevertheless largely influence the character of climates, and their effects ought not to be eliminated even although it could be done. The results which have been obtained in a jungle should not, however, as I have already said, be mixed up with those of other places which have a free exposure. The truth is that by adopting different kinds of protecting boxes, and by varying sufficiently their levels above the ground, we may so far depress the temperature of a hot country and exalt that of a colder, as instrumentally to equalise them.

There is but one mode of getting results which shall be comparable, and that is by adopting the same standard height and the same standard form of protecting box. The results may, however, be vitiated in another way by placing the instruments near or under shelter of buildings, or still more, by the monstrous system of fixing them to the walls of houses ; for masses of masonry or other building materials prevent either extreme from being recorded by the instruments. It must also be kept in view that however valuable continuous registrations may be, in showing intermediate variations of temperature, no photographic self-registering thermometer hitherto constructed gives any result which can be regarded as correct because it does not record the temperature of the air of the locality and is not comparable with those of common thermometers, nor even, perhaps, is ever comparable with those of other similar self-recording instruments. The house or framework with which the instruments are necessarily connected cannot fail variously to affect the mercury in the bulb and thus to veil the results. The only mode of counteracting this infuence is to have common thermometers in the neighbourhood placed and protected in the usual way and to record their indications eight or twelve times in the course of the twenty-four hours.

It must be kept in view that I have been speaking only of local climates, or those which are subordinate to the normal climate due to geographical position. That such great climatic zones due to latitude exist and vary as we recede from the equator towards the poles is abundantly evident, both from the animal and the vegetable world. The best mode of investigating these climatic zones would be to select stations as little affected as possible by surrounding vegetation, the instruments being exposed as freely as possible all round and placed at the same level above the ground, and as nearly as possible at the same level above the sea, so as to avoid confusion with what have been termed the climatic zones of altitude. For this purpose I venture to suggest the use of an instrument which I proposed in $1870^{1}{ }^{1}$ the indications of which depend on the heating up of a large quantity of watcr or other fluid contained in a thin glass globe which is freely exposed to the sun's rays. When the water expands under the influence of heat, the surplus fluid escapes into an adjoining vessel in which it can be afterwards weighed. On the other hand when the fluid is contracted by cold, the deficiency is continuously supplied from a connecting cistern kept always at the same, or sensibly the same, level. By this automatic arrangement the whole of the heat given out, however irregularly, by the sun, is constantly treasured up. The readings of maximum and minimum thermometers would also serve to correct errors due to the proximity of the tubes and cisterns of the instrument to which I have referred. The difference between the results of this and the common thermometer is the continuous registration of the alterations in bulk produced by the variations of temperature; whereas the common thermometer fails to record the many changes that take place between the maximum and minimum readings, and which are due to sudden obscurations and revelations of the sun caused by passing clouds during the day, while the terrestrial radiation at night is similarly affected. Even where this instrument is not used it would I think be an improvement on the present system were maximum and minimum thermometers kept constantly irrimersed in a large globe of thin glass filled with water.

THOMAS STEVENSON

\section{VOLCANIC PHENOMENA DURING I 875}

DR. GUSTAV TSCHERMAK'S Mineralogische Mittheilungen $(1876,2)$ contain a most interesting acoount of the volcanic occurrences during the year 1875 , computed by Prof. C. W. C. Fuchs. In the short introduction Dr. Fuchs expresses his regret that the scientific academies and societies do not give more general attention to this most important branch of geological research, and points out that through the numerous and universal relations of the institutions in question the statistics of volcanic eruptions and earthquakes would become far more correct in details and numbers, than it is in his own power to make them. The publication of the valuable information now given by Prof. Fuchs therefore all the more deserves the highest praise and attention. Dr. Fuchs divides the events into two classe;, viz., ertptions and earthquakes. The first volcano treated of is -

Etna.-After the short eruption of August 29, 1874, which lasted until the beginning of September, the mountain was perfectly at rest. Early in January, 1875, there were signs of new activity in the shape of repeated shocks, which, on the 8th, caused considerable damage near Acireale. But the shocks decreased again hoth in frequency and intensity, and a new period of rest ensued until the beginning of October. At that time a small crater on the south-side of the mountain became slightly active. From December 19 , smoke mixed with reddish vapours

$$
\text { I foumt. Scott. Mot. Soc, vol. iii. p. II } 4 \text {. }
$$

